\title{
ANALISIS GAYA KEPEMIMPINAN DEMOKRATIK DI PERPUSTAKAAN FAKULTAS EKONOMIKA DAN BISNIS UNIVERSITAS GADJAH MADA YOGYAKARTA
}

\author{
Nadia Amelia Qurrota A'yunin *
}

\begin{abstract}
Research that Analysis of Democratic Leadership Style in Library of Faculty of Economics and Business UGM Yogyakarta aims to analyze the leadership style of library leader (Chairman of Library Work Unit) FEB UGM whether to enter the democratic leadership style or not and to know the advantages and disadvantages of the Chairman of the Library Work Unit FE UGM in leading the library. The research method used in this research is descriptive qualitative method while the data collection with direct observation and interview with the leader and 3 (three) staff in the service and processing at the Library FEB UGM. The results showed that the leadership style in FEB UGM Library leads to democratic leadership style. In leading FEB UGM Library, the Head of Library Unit has advantages and disadvantages in the lead. The advantages and disadvantages are influenced by the personality (leadership personality). The advantages of leadership in the lead that is friendly, wise, ngemong, communicative, not authoritarian, motherly, good, open, can provide motivation and direction. While the shortcomings in the leadership that is sometimes less assertive in taking policy.
\end{abstract}

Keywords: Leadership Style, Democratic, Library FEB UGM

\section{Latar Belakang}

Perpustakaan perguruan tinggi (PT) merupakan unit pelaksana teknis (UPT) perguruan tinggi yang bersama-sama dengan unit lain turut melaksanakan Tri Dharma Perguruan Tinggi dengan cara memilih, menghimpun, mengolah, merawat, dan melayankan sumber

* Pustakawan Pertama Badan PPSDM Kesehatan Kemenkes RI Jl. Hang Jebat III Blok F3 Kebayoran Baru, Jakarta Selatan. email : nadiaamelia11@yahoo.co.id 
informasi kepada lembaga induknya pada khususnya dan masyarakat akademis pada umumnya. ${ }^{1}$

Kegiatan di sebuah perpustakaan dapat berlangsung secara optimal dengan adanya arahan dari pimpinan serta dilaksanakan bersama dengan staf untuk mencapai tujuan tertentu. Untuk dapat menciptakan suasana kerja yang harmonis dan tercapainya tujuan tertentu, dibutuhkan adanya kepemimpinan. Kepemimpinan merupakan tulang punggung pengembangan organisasi/lembaga karena tanpa adanya kepemimpinan yang baik tujuan organisasi akan sulit tercapai.

Kepemimpinan merupakan kegiatan sentral di dalam sebuah kelompok (organisasi), dengan seorang pimpinan puncak sebagai figur sentral yang memiliki wewenang dan tanggung jawab dalam mengefektifkan organisasi untuk mencapai tujuannya. Pemimpin sebagai figur sentral menyandang peran mempersatukan anggota organisasi yang terdiri dari individu-individu, agar menjadi satu kesatuan kekuatan yang bergerak kearah yang sama dalam melaksanakan volume dan beban kerja organisasi. ${ }^{2}$

Pencapaian organisasi itu sangat bergantung pada kualitas pemimpin baik kecerdasan emosi maupun kompetensi yang lain. Obsesi menghadirkan pimpinan yang benar-benar hebat untuk mendongkrak kinerja organisasi sudah menjadi fenomena universal. ${ }^{3}$

Dalam kepemimpinan, terdapat gaya kepemimpinan dari seorang pemimpin. Gaya kepemimpinan kepala perpustakaan secara langsung maupun tidak langsung mempunyai pengaruh terhadap kinerja karyawan perpustakaan yang dipimpinnya. Gaya kepemimpinan sejatinya ada tiga bentuk, yaitu : Otoriter, demokratis (demokratik) dan kepemimpinan bebas. Dari 3 gaya kepemimpinan tersebut, gaya kepemimpinan demokratis (demokratik) menurut penulis adalah gaya kepemimpinan yang ideal untuk di terapkan di organisasi perpustakaan.

Perpustakaan Fakultas Ekonomika dan Bisnis UGM Yogyakarta merupakan perpustakaan fakultas di Perguruan Tinggi yang dipimpin

\footnotetext{
${ }^{1}$ Shihabuddin Qalyubi. Dasar-dasar Ilmu Perpustakaan dan Informasi

(Yogyakarta: Jurusan Ilmu Perpustakaan dan Informasi Fakultas Adab UIN Sunan Kalijaga Yogyakarta, 2007), 10

${ }^{2}$ Sudaryono. Leadership : Teori dan Praktek Kepemimpinan (Jakarta: Lentera Ilmu Cendikia, 2014), 2

${ }^{3}$ Ibid, i
} 
oleh Ketua Unit Perpustakaan serta terdapat 8 (delapan) orang staf baik PNS maupun tenaga kontrak yang mengelola perpustakaan FEB UGM.

Berdasarkan latar belakang diatas, penulis tertarik untuk melakukan penelitian dengan menganalisis apakah gaya kepemimpinan di Perpustakaan FEB UGM masuk ke dalam gaya kepemimpinan demokratis serta penulis ingin mengetahui kelebihan dan kekurangan pemimpin dalam melakukan kepemimpinan di Perpustakaan FEB UGM.

\section{Rumusan Masalah}

1. Menganalisis gaya kepemimpinan pimpinan perpustakaan (Ketua Unit Kerja Perpustakaan) FEB UGM masuk ke dalam gaya kepemimpinan demokratik?

2. Apa kelebihan dan kekurangan Ketua Unit Kerja Perpustakaan FEB UGM dalam memimpin perpustakaan?

\section{Tinjauan Pustaka}

\section{Kepemimpinan}

Kepemimpinan adalah masalah relasi dan pengaruh antara pemimpin dan yang dipimpin. Kepemimpinan tersebut muncul dan berkembang sebagai hasil dari interaksi otomatis di antara pemimpin dan individu-individu yang dipimpin (ada relasi interpersonal). Kepemimpinan ini bisa berfungsi atas dasar kekuasaan pemimpin untuk mengajak, mempengaruhi, dan menggerakkan orang-orang lain guna melakukan sesuatu, demi pencapaian satu tujuan tertentu. ${ }^{4}$

Kepemimpinan dapat berjalan dengan lancar dan berhasil dalam melakukan inisiasi terhadap keompok perlu didukung oleh kemampuan pemimpin. Kemampuan tersebut merupakan modal utama yang perlu dipupuk dan dikembangkan dari waktu ke waktu. Kemampuan yang dimaksud sebagai modal utama ini berasal dari faktor intrinsik atau berada dalam diri seorang pemimpin itu sendiri. Modal utama tersebut adalah yang berujud: ${ }^{5}$

1) Ability

\footnotetext{
${ }^{4}$ Kartini Kartono. Pemimpn dan kepemimpinan : Apakah kepemimpinan abnormal itu? (Jakarta: Rajawali Press, 2016), 6

${ }^{5}$ Ambar Teguh Sulistiyani. Kepemimpinan Profesional : Pendekatan Leadership Games (Yogyakarta: Gava Media, 2008), 21-25
} 
Ability (kemampuan) adalah merupakan background yang dimiliki oleh pemimpin mengenai tingkat kemampuan, yang dapat meliputi pengetahuan, keahlian dan keterampilan baik yang diperoleh secara formal, non formal maupun bersumber dari pengalaman pribadi, yang bermanfaat bagi kepemimpinannya. Pengetahuan merupakan akumulasi dari apa yang terserap, baik melalui membaca, mengamati maupun mengalami.

2) Capability

Capability (kesanggupan) merupakan kondisi mental psikologis seseorang pemimpin yang mencerminkan kemantapan dan kesanggupan penuh untuk memikul segala konsekuensi jabatan, dan kepemimpinan.

3) Personality

Personality (kepribadian), lebih merupakan pancaran dari karakter pemimpin itu sendiri, yang menyangkut sifat, watak yang melekat pada dirinya. Personality ini terbentuk dari sifat-sifat genetis maupun lingkungan pendidikan.

Adapun skill yang harus dimiliki oleh seorang pemimpin agar kepemimpinannya menjadi efektif antara lain: ${ }^{6}$

1) Conceptual skill

Merupakan ketrampilan untuk dapat mengembangkan ide dan kerangka pemikiran sehinga dalam membuat keputusan organisasi dapat dilakukan dengan baik. Pemimpin harus mempunyai wawasan luas, baik menyangkut masalah intern organisasi maupun ekstern.

2) Humas skill

Merupakan kemampuan seorang pemimpin untuk melakukan hubungan dengan orang lain. Ketrampilan ini berkaitan erat dengan permasalahan bagaimana pemimpin membina hubungan dengan anak buah, sesama pemimpin setingkat atau pemimpin diatasnya.

3) Technical skill

Keterampilan teknis meliputi pengetahuan tentang metode, proses, dan perlengkapan untuk melakukan aktivitas khusus dari unit organisatoris manajer itu. Keterampilan teknis juga meliputi pengetahuan faktual tentang organisasi (peraturan, 
struktur, sistem manajemen, karakteristik karyawan), dan pengetahuan tentang produk dan jasa organisasi (spesifikasi teknis, kekuatan dan keterbatasan). Jenis pengetahuan yang diperoleh dengan kombinasi antara pendidikan formal, pelatihan, dan pengalaman kerja.

\section{Gaya Kepemimpinan}

Gaya kepemimpinan adalah pola perilaku yang diperlihatkan ketika mencoba memengaruhi aktivitas orang lain sesuai dengan yang dipersepsikan oleh orang tersebut. ${ }^{7}$ Gaya kepemimpinan sejatinya ada tiga bentuk, yaitu: ${ }^{8}$

1) Otoriter (Authoritarian Leadership)

Kekuasaan otoriter gaya kepemimpinannya berdasarkan pada kekuasaan yang mutlak dan penuh. Dengan kata lain, sang pemimpin yang dalam kepemimpinan ini disebut juga sebagai diktator, bertindak mengarahkan pikiran, perasaan dan perilaku orang lain kepada suatu tujuan yang telah ditetapkannya. Artinya, segala ketentuan dan keputusan berada di tangan si pemimpin.

2) Demokratis (Democratic Leardership)

Gaya kepemimpinan demokratis adalah gaya atau cara memimpin yang demokratis, dan bukan karena dipilihnya si pemimpin secara demokratis. Gaya yang demokratis seperti ini misalnya saja si pemimpin memberikan kebebasan dan keleluasaan kepada para bawahan dan pengikutnya untuk mengemukakan pendapatnya, saran dan kritikannya dan selalu berpegang pada nilai-nilai demokrasi pada umumnya.

3) Kepemimpinan Bebas (Laisez faire Leadership)

Dalam kepemimpinan jenis ini, sang pemimpin biasanya menunjukkan suatu gaya dan perilaku yang pasif dan juga sering kali menghindari dirinya dari tanggung jawab. Dalam praktiknya, si pemimpin hanya menyerahkan dan menyediakan instrumen dan sumber-sumber yang diperlukan oleh anak buahnya untuk melaksanakan pekerjaan untuk mencapai tujuan yang ditetapkan pimpinan.

\footnotetext{
${ }^{7}$ Wirawan. Kepemimpinan: Teori, Psikologi, Prilaku Organisasi, Aplikasi dan Penelitian (Jakarta: Raja Gravindo Persada, 2013), 352

${ }^{8}$ Veithzal Rivai. Pemimpin dan Kepemimpinan Dalam Organisasii (Jakarta: Rajawali Press, 2014), 136-137
} 
Pimpinan yang memiliki gaya ini memang berada diantara anak buahnya, akan tetapi tidak memberikan motivasi, pengarahan dan petunjuk, dan segala pekerjaan diserahkan kepada anak buahnya. Berikut adalam perbedaan antara ke tiga gaya kepemimpinan tersebut.

Tabel 1. Tiga Macam Gaya Kepemimpinan ${ }^{9}$

\begin{tabular}{|c|c|c|}
\hline OTORITER & DEMOKRATIS & LAISEZ-FAIRE \\
\hline $\begin{array}{l}\text { Semua determinasi } \\
\text { "policy"dilakukan oleh } \\
\text { pemimpin }\end{array}$ & $\begin{array}{l}\text { Semua "policies" } \\
\text { merupakan bahan } \\
\text { pembahasan kelompok } \\
\text { dan keputusan } \\
\text { kelompok yang } \\
\text { dirangsang dan dibantu } \\
\text { oleh pemimpin }\end{array}$ & $\begin{array}{l}\text { Kebebasan lengkap } \\
\text { untuk keputusan } \\
\text { kelompok atau individual } \\
\text { dengan minimum } \\
\text { partisipasi pemimpin }\end{array}$ \\
\hline $\begin{array}{l}\text { Teknik-teknik dan } \\
\text { langkah-langkah aktivitas } \\
\text { ditentukan oleh pejabat } \\
\text { satu persatu, hingga } \\
\text { langkah-langkah } \\
\text { mendatang senantiasa } \\
\text { tidak pasti }\end{array}$ & $\begin{array}{l}\text { Perspektif aktivitas } \\
\text { dicapai selama diskusi } \\
\text { berlangsung. Dilukiskan } \\
\text { langkah-langkah umum } \\
\text { ke arah tujuan } \\
\text { kelompok dan apabila } \\
\text { diperlukan nasihat } \\
\text { teknis,maka pemimpin } \\
\text { menyarankan dua atau } \\
\text { lebih banyak prosedur } \\
\text { alternatif yang dipilih } \\
\end{array}$ & $\begin{array}{l}\text { Macam-macam bahan } \\
\text { disediakan oleh } \\
\text { pemimpin, yang dengan } \\
\text { jelas mengatakan bahwa } \\
\text { ia akan menyediakan } \\
\text { keterangan apabila ada } \\
\text { permintaan, ia tidak } \\
\text { turut berpartisipasi } \\
\text { bagian dalam diskusi } \\
\text { kelompok }\end{array}$ \\
\hline $\begin{array}{l}\text { Pemimpin biasanya } \\
\text { mendikte tugas } \\
\text { pekerjaan khusus dan } \\
\text { teman sekerja setiap } \\
\text { anggota }\end{array}$ & $\begin{array}{l}\text { Para anggota bebas } \\
\text { untuk bekerja dengan } \\
\text { siapa yang mereka } \\
\text { kehendaki dan } \\
\text { pembagian tugas } \\
\text { terserah pada } \\
\text { kelompok }\end{array}$ & $\begin{array}{l}\text { Pemimpin tidak } \\
\text { berpartisipasi sama } \\
\text { sekali. }\end{array}$ \\
\hline $\begin{array}{l}\text { "Dominator" cenderung } \\
\text { bersikap pribadi dalam } \\
\text { pujian dan kritik } \\
\text { pekerjaan setiap } \\
\text { anggota, ia tidak turut } \\
\text { serta dalam partisipasi } \\
\text { kelompok secara aktif } \\
\text { kecuali apabila ia } \\
\text { memberikan } \\
\text { demonstrasi }\end{array}$ & $\begin{array}{l}\text { Pemimpin bersifat } \\
\text { objektif dalam pujian } \\
\text { dan kritiknya dan ia } \\
\text { berusaha untuk } \\
\text { menjadi anggota } \\
\text { kelompok secara } \\
\text { mental, tanpa } \\
\text { terlampau banyak } \\
\text { melakukan pekerjaan } \\
\text { tersebut. }\end{array}$ & $\begin{array}{l}\text { Komentar spontan yang } \\
\text { tidak frekuen atas } \\
\text { aktivitas anggota dan ia } \\
\text { tidak berusaha sama } \\
\text { sekali untuk menilai atau } \\
\text { mengatur kejadian- } \\
\text { kejadian. }\end{array}$ \\
\hline
\end{tabular}




\section{Gaya Kepemimpinan Demokratik/Demokratis}

Gaya Kepemimpinan Demokratis adalah Gaya kepemimpinan demokratis adalah gaya atau cara memimpin yang demokratis, dan bukan karena dipilihnya si pemimpin secara demokratis. Gaya yang demokratis seperti ini misalnya saja si pemimpin memberikan kebebasan dan keleluasaan kepada para bawahan dan pengikutnya untuk mengemukakan pendapatnya, saran dan kritikannya dan selalu berpegang pada nilai-nilai demokrasi pada umumnya. ${ }^{10}$

Adapun ciri-ciri kepemimpinan demokratis antara lain: ${ }^{11}$

1) Keputusan dan kebijakan

Keputusan dan kebijakan dibuat bersama dengan bawahan

2) Wewenang

Wewenang pimpinan tidak multak. Pemimpin bersedia untuk melimpahkan sebagia wewenangnya kepada orang lain

3) Komunikasi

Komunikasi berlangsung timbal balik. Komunikas antara pimpinan dan bawahan berjalan dengan baik, sehingga semua informasi kerja diketahui semua komponen yang terkait

4) Pengawasan

Pemimpin melakukan pengawasan secara wajar terhadap sikap, tingkah laku dan perbuatan atau kegiatan bawahan.

5) Pemimpin menerima saran dari bawahan

Pemimpin banyak memberi kesempatan kepada bawahan untuk memberikan saran, pertimbangan dan pendapat dalam menyelesaikan pekerjaan

6) Pelaksanaan tugas

Pemberian tugas kepada bawahan lebih bersifat permintaan dari pada instruksi kerja.

7) Kritik dan pujian

\footnotetext{
${ }^{10}$ Veithzal Rivai. Pemimpin dan Kepemimpinan Dalam Organisasi, 136

11 Open Nikolaus. Hubungan Antara Kepemimpinan Tipe Demokratis Kepala Desa Dengan Partisipasi Masyarakat Dalam Membangun Desa Di Kecamatan Titehena Kabupaten Flores Timur. Jurnal Administrasi Pubik dan Birokrasi Vol.1 No. 1, 2014, artikel 5 Diakses dalam http://pasca.ut.ac.id/journal/index.php/JAPB/article/view/18/18, pada tanggal 5 januari 2018 pk. 12.11
} 
Pemimpin memberikan pujian dan kritik yang seimbang. Pemimpin memberikan pujian kepada bawahan yang bekerja dengan baik, tetapi memberi kritik yang membangun untuk meningkatkan semangat bawahan dalam bekerja.

8) Penyelesaian tugas

Pimpinan mendorong bawahan untuk menyelesaikan tugas dengan sempurna dalam batas kemampuan yang wajar. Pimpinan tidak memaksakan bawahan untuk bekerja melampaui kemampuan bawahannya

9) Tindakan dan sikap

Pimpinan memperhatikan aspek perasaan dari bawahan ketika pemimpin bersikap dan bertindak

10) Suasana kerja kondusif

Adanya suasana dan saling percaya, saling hormat dan saling menghargai antara pimpinan dan bawahan

11) Tanggung jawab organisasi dipikul bersama

\section{Perpustakaan FEB UGM}

Perpustakaan Fakultas Ekonomika dan Bisnis UGM adalah salah satu unit pendukung kegiatan fakultas di Fakultas Ekonomika dan Bisnis (FEB) Universitas Gadjah Mada. Sebagai implementasi Tri Dharma Perguruan Tinggi seperti pendidikan dan pembelajaran, penelitian, dan pelayanan publik, khususnya di bidang ekonomi dan bidang usaha (akuntan, manajemen, dan ekonomi). Kehadiran Perpustakaan juga untuk mendukung visi dan misi FEB dan UGM, terutama untuk menjadi universitas riset internasional.

Perpustakaan FEB memiliki dua lokasi, yaitu unit 1 (terletak di lantai satu, di sebelah utara gedung sarjana) dan unit 2 (terletak di lantai satu gedung doktor dan program sarjana). Perpustakaan unit 1 khusus untuk administrasi, keanggotaan dan layanan sirkulasi (koleksi buku), dan kemudian Perpustakaan unit 2 khusus untuk layanan publikasi berkala, referensi dan tesis. Perpustakaan FEB UGM dipimpin oleh Ketua Unit Perpustakaan dan terdapat 8 staf di dalam pengelolaan Perpustakaan. Berikut ini adalah data profil Ketua Unit Kerja Perpustakaan beserta stafnya. 
Tabel 2. Profil SDM Perpustakaan Fakultas Ekonomika dan Bisnis UGM Tahun 2018

\begin{tabular}{|c|l|l|l|l|}
\hline No & \multicolumn{1}{|c|}{ Nama } & Pendidikan & \multicolumn{1}{c|}{$\begin{array}{c}\text { Status } \\
\text { Kepegawaian }\end{array}$} & \multicolumn{1}{|c|}{ Jabatan } \\
\hline 1 & $\begin{array}{l}\text { Maryatun, S.E., } \\
\text { M.A }\end{array}$ & S2 & PNS & $\begin{array}{l}\text { Ketua Unit Kerja } \\
\text { Perpustakaan }\end{array}$ \\
\hline 2 & Rini Widati, A.Md & D3 & PNS & Koordinator Unit II \\
\hline 3 & Sudibyo, A.Md & D3 & PNS & $\begin{array}{l}\text { Koordinator Unit I } \\
\text { Pelayanan Sirkulasi }\end{array}$ \\
\hline 4 & $\begin{array}{l}\text { Heni Purwaningsih, } \\
\text { A.Md., SIP }\end{array}$ & S1 & Pegawai Tetap & Pustakawan \\
\hline 5 & $\begin{array}{l}\text { Eko Hariyanto, } \\
\text { A.Md., SIP }\end{array}$ & S1 & Pegawai tetap & Pustakawan \\
\hline 6 & $\begin{array}{l}\text { Handy Firmansyah, } \\
\text { A.Md }\end{array}$ & D3 & $\begin{array}{l}\text { Pegawai tidak } \\
\text { tetap }\end{array}$ & Pustakawan \\
\hline 7 & Waluyo, S.Sos & S1 & $\begin{array}{l}\text { Pegawai tidak } \\
\text { tetap }\end{array}$ & Staf administrasi \\
\hline 8 & Heru Wibowo, SIP & S1 & $\begin{array}{l}\text { Pegawai } \\
\text { kontrak }\end{array}$ & Asisten Pustakawan \\
\hline 9 & $\begin{array}{l}\text { Ratih Nurhidayah, } \\
\text { SIP }\end{array}$ & S1 & $\begin{array}{l}\text { Pegawai } \\
\text { kontrak }\end{array}$ & Asisten Pustakawan \\
\hline
\end{tabular}

Sumber : http://lib.feb.ugm.ac.id/profile/librarian/

\section{Metode Penelitian}

Metode penelitian yang digunakan dalam makalah ini yaitu metode kualitatif deskriptif. Sedangkan pengumpulan data dengan observasi secara langsung dan wawancara dengan 3 (tiga) orang staf dan Ketua Unit Kerja Perpustakaan Fakultas Ekonomika dan Bisnis Universitas Gadjah Mada Yogyakarta.

\section{Hasil Dan Pembahasan}

Analisis Gaya Kepemimpinan Demokratik Pimpinan Unit Kerja Perpustakaan (Ketua Unit Kerja Perpustakaan) FEB UGM

Berdasarkan hasil observasi secara langsung dan wawancara dengan Ketua Unit Perpustakaan beserta stafnya serta dianalisis, maka didapatkan hasil bahwa gaya kepemimpinan di FEB UGM mengarah pada gaya kepemimpinan demokratik. Adapun ciri-ciri kepemimpinan demokratis antara lain:

1) Keputusan dan kebijakan dibuat bersama dengan bawahan.

Berdasarkan hasil wawancara, didapatkan data bahwa pimpinan selalu mengadakan rapat rutin 3 bulan sekali untuk 
menyusun rencana kerja dan membahas persoalan di Perpustakaan. Semua staf dilibatkan di dalam rapat tersebut, dan staf diberikan kesempatan untuk menyampaikan pendapat dan masukan untuk perencanaan prorgam kerja.

2) Komunikasi berlangsung timbal balik. Komunikasi antara pimpinan dan bawahan berjalan dengan baik, sehingga semua informasi kerja diketahui semua komponen yang terkait.

Dari hasil observasi dan wawancara, komunikasi yang dilakukan oleh pimpinan dan staf berjalan dengan baik, setiap hari pimpinan pasti menyapa stafnya dan selalu menanyakan kepada staf terkait pekerjaan. Jika ada masalah terdapat wa grup jadi, dapat langsung sharing dan mendapatkan respon.

3) Pemimpin melakukan pengawasan secara wajar terhadap sikap, tingkah laku dan perbuatan atau kegiatan bawahan.

Berdasarkan hasil wawancara dengan pimpinan, didapatkan data bahwa jika ada stafyang melakukan kesalahan di dalam pekerjaan, pimpinan hanya mengingatkan saja untuk tidak ulangi lagi kesalahannya dan biasanya tidak menegur per individu tetapi disampaikan pada saat rapat koordinasi untuk pembelajaran bersama.

4) Pemimpin menerima saran dari bawahan. Pemimpin banyak memberi kesempatan kepada bawahan untuk memberikan saran, pertimbangan dan pendapat dalam menyelesaikan pekerjaan

Berdasarkan hasil wawancara dengan pimpinan dan staf, didapatkan data bahwa pimpinan selalu memberikan kesempatan kepada semua staf tanpa membedakan status kepegawaian baik PNS maupun tenaga kontrak, mereka mendapatkan kesempatan yang sama untuk dapat menyampaikan masukan, saran dan pendapat untuk hal pekerjaan maupun pengembangan perpustakaan.

5) Pelaksanaan tugas. Pemberian tugas kepada bawahan lebih bersifat permintaan dari pada instruksi kerja.

Berdasarkan hasil wawancara dengan staf, didapatkan data bahwa pimpinan perpustakaan memberikan instruksi yang jelas dalam memberikan tugas kepada staf, seperti yang diungkapkan ratih (staf bag. Pelayanan) mengenai instruksi yang diberikan pimpinan : "Jelas. Instruksi sifatnya teoritis, jika dilapangan tidak terjadi kesesuaian, bisa didiskusikan lagi" 
6) Kritik dan pujian

Pemimpin memberikan pujian dan kritik yang seimbang. Pemimpin memberikan pujian kepada bawahan yang bekerja dengan baik, tetapi memberi kritik yang membangun untuk meningkatkan semangat bawahan dalam bekerja.

Berdasarkan hasil observasi dan wawancara, didapatkan data bahwa jika jika ada staf yang melakukan kesalahan dalam pekerjaan, pimpinan hanya mengingatkan saja, agar tidak mengulanginya lagi dan disampaikan saat rapat koordinasi untuk pembelajaran bersama. Bagi staf yang rajin/dapat menyelesaikan pekerjaan dengan baik, maka pimpinan memberikan pujian saat rapat koordinasi untuk dapat dicontoh staf yang lain dan sifatnya memberikan motivasi kepada yang lainnya, seperti yang telah dipaparkan pimpinan jika ada staf yang rajin/dapat menyelesaikan pekerjaan : "Paling ketika ada brieving, memberikan pujian saat rapat koordinasi untuk dapat dicontoh teman-teman yang lain"

7) Penyelesaian tugas

Pimpinan mendorong bawahan untuk menyelesaikan tugas dengan sempurna dalam batas kemampuan yang wajar. Pimpinan tidak memaksakan bawahan untuk bekerja melampaui kemampuan bawahannya.

Dari hasil wawancara dengan staf dan pimpinan, pimpinan memberikan suatu pekerjaan kepada stafnya dengan memperhatikan kompetensi yang dimiliki stafnya. Menurut pimpinan : "Tergantung jenis pekerjaannya, kalau pekerjaan khusus, dilihat sesuai kompetensinya, kalau umum bagi rata" dan menurut ratih (staf bagian pelayanan) dalam pembagian tugas: "Sesuai dengan kompetensi, jika ada tugas tambahan diklarifikasi dulu, misalnya ada pekerjaan diluar bidang perpustakaan, Ibu biasanya konfirmasi dahulu kepada YBS mampu tidak melakukan tugas yang akan diberikan".

8) Tindakan dan sikap

Pimpinan memperhatikan aspek perasaan dari bawahan ketika pemimpin bersikap dan bertindak.

Berdasarkan hasil wawancara dengan staf, maka didapatkan data bahwa pimpinan tidak pernah mengeluarkan kata-kata yang menyakiti perasaan stafnya seperti yang disampaikan salah satu staf, jika ada yang melakukan kesalahan: "Biasanya kalau hal-hal kecil, 
bukan menegur, tapi lebih mengarahkan, tidak ada kata-kata yang keras, lebih ke konfirmasi, Cuma diarahkan, tidak pernah sampai menyakiti hati “

9) Suasana kerja kondusif

Adanya suasana dan saling percaya, saling hormat dan saling menghargai antara pimpinan dan bawahan.

Berdasarkan hasil wawancara dengan staf dan pimpinan, maka didatkan data bahwa suasana kerja di Perpustakaan FEB berlangsung secara kondusif, jika ada permasalahan langsung dapat diselesaikan dengan kekeluargaan, pimpinan tidak bersifat otoriter, tetapi memimpin secara kekeluargaan (lebih mengayomi staf). Sesuai dengan yang diungkapkan pimpinan tentang suasana kerja di Perpustakaan FEB UGM : "Menyenangkan, karena banyak yang bisa dilakukan, pengelola fakultas mendukung kegiatan yang dilakukan Perpustakaan FEB". Menurut Ratih dan Sudibyo (staf bag. Pelayanan) saat diwawancarai menyatakan bahwa suasana kerja di Perpustakaan FEB cukup nyaman. Pernyataan tersebut juga diperjelas dengan Heny (staf Bag. Pengolahan) yang menyatakan : "Suasana kerja kondusif, semua Kegiatan terlaksana sesuai job description masing-masing".

10) Tanggung jawab organisasi dipikul bersama

Berdasarkan hasil observasi dan wawancara, maka didapatkan data bahwa tanggung jawab organisasi dipikul bersama. Pimpinan dan staf secara bersama melakukan rapat koordinasi perencanaan, kemudian ada pembagian tugas pekerjaan sesuai kompetensi masing-masing, kemudian dilaksanakan dan dikoordinasikan dengan pimpinan jika mengalami kendala di dalam penyelesaian pekerjaan tersebut.

\section{Kelebihan dan Kekurangan Kepemimpinan Ketua Unit Kerja Perpustakaan FEB UGM}

Berdasarkan hasil wawancara dengan 3 (tiga) orang staf Perpustakaan FEB UGM maka didapatkan hasil bahwa 2 (dua) orang staf menyatakan bahwa karakter pimpinan Perpustakaan FEB (Ibu Maryatun) yaitu ramah, bijak, ngemong, komunikatif, tidak otoriter, keibuan, baik, terbuka, bisa memberikan motivasi dan arahan.

Selain kelebihan, terdapat kekurangan di dalam karakter pimpinan di dalam memimpin perpustakaan. Berdasarkan hasil wawancara dengan 3 (tiga) orang staf, 1(satu) orang staf menyatakan bahwa tidak ada kekurangan pimpinan di dalam memimpin 
perpustakaan, sedangkan 2 (dua) orang staf menyatakan bahwa pimpinan terkadang kurang tegas di dalam mengambil kebijakan seperti yang diutarakan salah satu staf bag. Pelayanan : "Karena Ibu ramah banget, terkadang muncul kurang tegas, malah bisa melemahkan kebijakan, karena suka gak tegaan (terlalu baik)".

\section{Kesimpulan}

1. Berdasarkan hasil observasi dan wawancara dengan pimpinan dan staf di Perpustakaan FEB UGM, kemudian penulis menganalisis berdasarkan ciiri-ciri gaya kepemimpinan demokratik maka didapatkan hasil bahwa gaya kepemimpinan di FEB UGM mengarah pada gaya kepemimpinan demokratik.

2. Di dalam memimpin Perpustakaan FEB UGM, Ketua Unit Perpustakaan memiliki kelebihan dan kekurangan di dalam memimpin. Kelebihan dan kekurangan tersebut dipengaruhi oleh kepribadian (personality) pimpinan. Adapun kelebihan pimpinan di dalam memimpin yaitu ramah, bijak, ngemong, komunikatif, tidak otoriter, keibuan, baik, terbuka, bisa memberikan motivasi dan arahan. Sedangkan kekurangan di dalam kepemimpinannya yaitu terkadang kurang tegas di dalam mengambil kebijakan.

\section{Daftar Pustaka}

Buku :

Kartono, Kartini. Pemimpin dan Kepemimpinan : Apakah Kepemimpinan Abnormal Itu?. Jakarta : Rajawali Press, 2016.

Qalyubi,Shihabuddin. Dasar-dasar Ilmu Perpustakaan dan Informasi, Yogyakarta: Jurusan Ilmu Perpustakaan dan Informasi Fakultas Adab UIN Sunan Kalijaga Yogyakarta, 2007.

Rivai, Veithzal, dkk. Pemimpin dan Kepemimpinan Dalam Organisasi, Jakarta : Rajawali Press, 2014.

Sudaryono. Leadership: Teori dan Praktek Kepemimpinan. Jakarta : Lentera Ilmu Cendikia, 2014.

Sulistiyani, Ambar Teguh. Kepemimpinan Profesional : Pendekatan Leadership Games, Yogyakarta: Gava Media, 2008.

Wirawan. Kepemimpinan : Teori, Psikologi, Prilaku Organisasi, Aplikasi dan Penelitian, Jakarta : Raja Gravindo Persada, 2013. 


\section{Jurnal :}

Nikolaus, Open. Hubungan Antara Kepemimpinan Tipe Demokratis Kepala Desa Dengan Partisipasi Masyarakat Dalam Membangun Desa Di Kecamatan Titehena Kabupaten Flores Timur. Jurnal Administrasi Pubik dan Birokrasi Vol.1 No. 1, 2014, artikel 5 Diakses dalam http://pasca.ut.ac.id/journal/index.php/JAPB/article/view/18/1 8, pada tanggal 5 januari 2018 pk. 12.11

\section{Sumber Internet:}

http://lib.feb.ugm.ac.id/profile/librarian/, diakses pada tanggal 10 Januari 2018 pk.08.15 